\title{
$\widehat{A}$ Madridge \\ madridge Journal of Case Reports and Studies \\ Interconnecting Scientific World
}

Case Report

Open Access

\section{Rupture of the Right Valsalva Sinus with Significant Left-To-Right Shunt}

\author{
Katarína Kubišová ${ }^{\star}$ \\ Professor, Cardiovascular center, Nemocnice AGEL, Třinec- Podlesí, Czech Republic
}

\section{Article Info}

\author{
*Corresponding author: \\ Katarína Kubišová \\ Professor \\ Cardiovascular center \\ Nemocnice AGEL, Třinec- Podlesí \\ Czech Republic \\ Tel: +420558304111 \\ E-mail: kubis.katarina@gmail.com
}

\section{Received: May 15, 2017}

Accepted: June 24, 2017

Published: July 3, 2017

Citation: Kubišová K. Rupture of the Right Valsalva Sinus with Significant Left-To-Right Shunt. Madridge J Case Rep Stud. 2017; 1(1): 20-23.

doi: $10.18689 /$ mjcrs-1000105

Copyright: @ 2017 The Author(s). This work is licensed under a Creative Commons Attribution 4.0 International License, which permits unrestricted use, distribution, and reproduction in any medium, provided the original work is properly cited.

Published by Madridge Publishers

\begin{abstract}
Valsalva sinus aneurysm (VSA) is a rare heart disease which is most frequently congenital. Even though it can be asymptomatic, there is a danger of expansion and rupture resulting in heart failure.

Our case report discusses a 25 year old male without any significant medical history being evaluated for dyspnea and fever. Right Valsalva sinus rupture was diagnosed and the patient was treated surgically.

\section{Overview}

Valsalva sinus aneurysm is a rare anomaly which is either congenital or acquired. Congenital aneurysm is a more common type which comprises $0,1-3,5 \%$ of all congenital heart diseases.
\end{abstract}

Keywords: Right Valsalva Sinus; Valsalva sinus aneurysm; Connective tissue; Aorta.

\section{Case Report}

25 year old male, who had been followed for systolic arterial hypertension for a couple of years, not using any medications, was transferred to our department from a local hospital where he was hospitalized for fever, cough and exertional dyspnea of sudden onset. Patient was treated empirically with antibiotics (Doxycycline) for a suspected respiratory infection. As a part of diagnostic evaluation, chest X-ray was performed which showed lung congestion and enlarged cardiac silhouette. Echocardiography followed, with a suspicion of ventricular septal defect and patient was sent for evaluation to our hospital.

During physical examination, a systolic-diastolic murmur could be appreciated parasternally at the 5th left intercostal space. No objective signs of heart failure were found. Blood pressure was $175 / 60$ at the time of admission. ECG showed sinus tachycardia, $100 \mathrm{bpm}$, and incomplete right bundle branch block. Lab results were insignificant and inflammatory markers negative. Transthoracic and transesophageal $\mathrm{ECHO}$ followed in the evaluation process. It showed slight dilatation of right- and left sided heart chambers. 7-8 millimeters wide communication with turbulent flow was found between right atrium and right coronary sinus. Using Doppler, peak gradient was $90 \mathrm{mmHg}$ at the site of the defect. Aortic valve was without any stenosis or regurgitation, being formed with three cusps. There was a slight tricuspid regurgitation seen. Interventricular and interatrial septa were intact. Coronary angiography showed normal arteries without any stenoses, aortography confirmed the communication between right atrium and aorta. For even more detailed evaluation, a cardiac MRI was performed. 


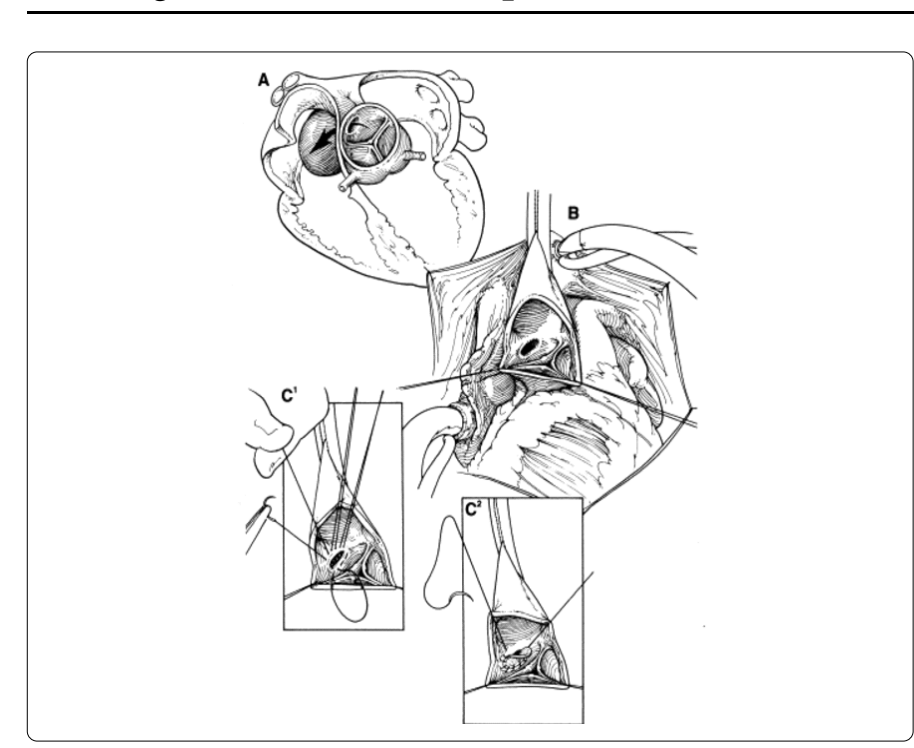

Figure 1. Sture of rupture Sinus of Valsalva

Source: Sinus of valsalva aneurysm or fistula : management and outcome, Thomas J Takach

Magnetic resonance confirmed the defect as well, the size of 7 millimeters with continuous left to right shunting, which was seen near the area of the attachment of the septal tricuspid cusp. In the dynamic sequences in coronary and transversal planes (modified to evaluate aortic bulbus), a variable derivation of the jet was seen, probably depending on the tricuspid cusps movement. According to the volumetric analysis, both ventricles were dilated. Figure.1. End diastolic volume of the left was $257 \mathrm{ml}$, while the volume of the right was $219 \mathrm{ml}$. Using the phase contrast method, the flow in the aorta and pulmonary trunk was evaluated. Stroke volume to the aorta was $57 \mathrm{ml}$, while the volume ejected to the pulmonary artery was found to be $152 \mathrm{ml}$. With the pulmonary and systemic flow ratio (Qp:Qs) being 2,6:1, Hemo dynamically significant left-to-right shunt was confirmed.

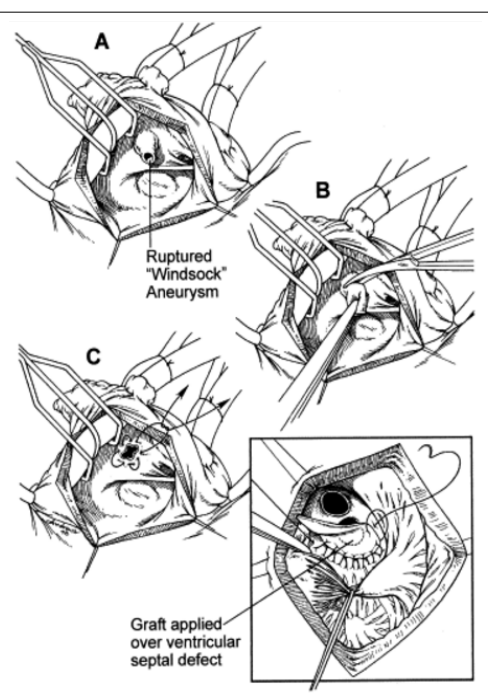

Figure 2. Patch of rupture sinus of Valsalva

Source: Sinus of valsalva aneurysm or fistula : management and outcome, Thomas J Takach et al.

Patient was discharged from the hospital in a cardiopulmonary stable state and came two weeks later for a surgical repair of the defect. Patient was put on a cardiopulmonary bypass and a patch was used to close the ruptured site. Figure 2. Preoperatively, transesophageal echocardiography showed no residual shunting and the operation was uneventful. Postoperative course was uncomplicated and transthoracic ECHO failed to show any pathologic communication between heart chambers and the aorta, pericardium was without effusion. Patient was discharged home 6 days after the repair. He remains asymptomatic and without residual shunt 2 years after the operation.

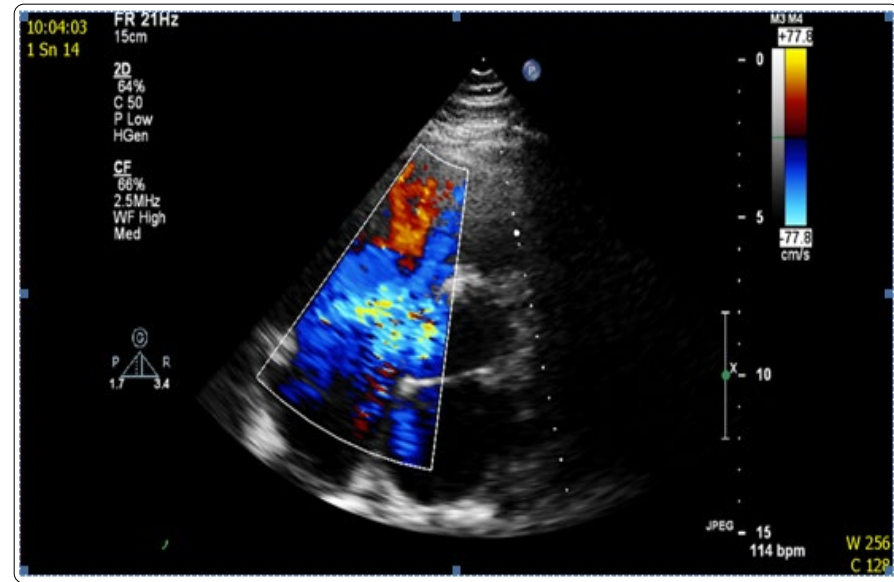

Figure 3. Displayed communication between right sinus of Valsalva and right anteroom with L-R short circuits according to transesophageal echo examination.

\section{Discussion}

Congenital aneurysm of Valsalva sinus is a consequence of the absence of muscular and elastic connective tissue in the wall of the aorta, in the Valsalva sinus area [12]. The acquired aneurysms are usually caused by aortic wall disruption due to endocarditis, syphillis, tuberculosis or trauma. Degenerative diseases like atherosclerosis or cystic median necrosis also play a role. Figure 3. Right Valsalva sinus is affected in $94 \%$ of cases, being followed by non-coronary sinus [5\%] and left coronary sinus comprising only $1 \%$ of cases [13]. Aneurysms without rupture are usually asymptomatic, however they can cause, by their expansive nature, complications such as coronary artery compression with resulting myocardial ischemia [2], arrhythmias, tricuspid insufficiency, aortic regurgitation or, very rarely, a right ventricular outflow tract obstruction [3].

The degree of hemodynamic effect, caused by a rupture of Valsalva sinus aneurysm, is determined by the amount of blood flowing through the defect and by the fact how acutely the defect is created.

Aneurysm rupture located to the right or non coronary sinus of Valsalva communicates with right sided heart chambers, resulting in a left-to-right shunting [1]. In the case of aneurysm rupturing into the pericardial sac, a cardiac tamponade may occur.

Valsalva sinus aneurysm may be an isolated congenital heart defect, or it may be present with other congenital anomalies such as per membranous inter ventricular septal defect, bicuspid aortic valve, aortic regurgitation and, less 
frequently, pulmonary stenosis, aortic coarctation or atrial septal defect. Approximately $10 \%$ of patients with Marfan syndrome have some type of Valsalva sinus aneurysm.

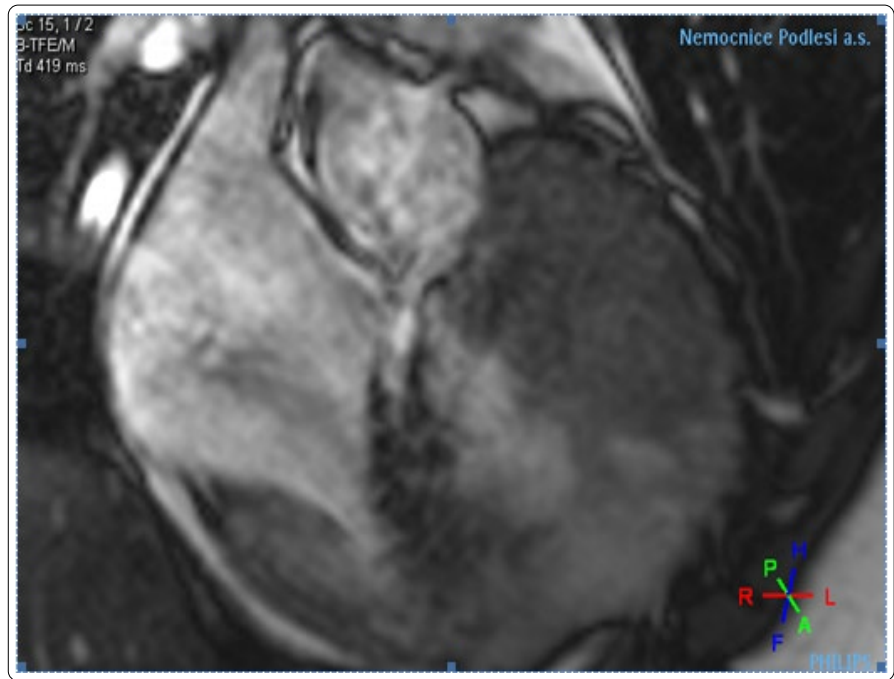

Figure 4. Displayed communication between right sinus of Valsalva and right vestibule with L-R short circuits according to MRI of heart.

Valsalva sinus aneurysm endangers it's carriers with possible rupture, leading to progressive heart failure, which can even be fatal [4].

Aneurysms that don't rupture are usually asymptomatic and may be accidentally found using echocardiography in patients older than 60 years. Ruptured Valsalva sinus aneurysm is predominantly diagnosed between adolescence and 30 years of age [4].

Valsalva sinus aneurysm rupture presents mainly as dyspnea, cough, less frequently as chest pain, syncope (when the right ventricular outflow tract gets obstructed) and very rarely as infective endocarditis [5]. The experience with treating Valsalva sinus aneurysm is limited since the prevalence of the disease is low. Authors of many publications agree that surgical correction is a procedure with low risk of mortality and good postoperative results. Figure 4. When Valsalva sinus aneurysm is not joined with other anomalies, the surgeon usually decides between primary suture and patch, while the suture itself has been connected with postoperative dehiscence more frequently, resulting more often in the need for reoperation $[7,8]$.

Primary suture of the ruptured Valsalva sinus is therefore recommended only in small defects or nonruptured sinuses [8]. Aortic valve needs to be replaced in the case of its damage (for example resulting in significant regurgitation, infective endocarditis) [10]. The next option is Valsalva sinus aneurysm closure using Amplatz occluder. There is very limited experience with this procedure. A few case reports and one larger study with 20 patients have been published to this day. The study showed successful occluder implantation in 18 patients (from the cohort of 20), while in 5 of them a residual shunt could have been detected. During the next 2 years of follow up, the residual shunt was observed to spontaneously decrease and was then marked as hemo dynamically insignificant [11]. Due to the small size of published studies, that lack statistical analysis comparing safety and success rate of surgical and interventional procedures, transcatheter approach still cannot be regarded as an well defined alternative to the surgical closure [11]. According to the Czech society of cardiology, Valsalva sinus aneurysm is indicated for operation in following cases: when having more than 50 millimeters in size, when compressing adjacent tissues, when getting larger fast or after a rupture [9].

In our case, the patient was diagnosed and treated correctly fairly soon, preventing serious hemodynamic complications that possibly could have been fatal. Based on the available literature, patients with a ruptured Valsalva sinus aneurysm die during the first year after the symptoms appear, due to a heart failure [4]. The question is whether we timed the surgical correction in our patient with significant left-toright shunting correctly. All we know from the available literature is the fact that the closing procedure should be done early. We do not have any specific data showing that it is safe to discharge the patient home for a few days before the elective surgery as it was done in our case.

\section{Conclusion}

Clinical suspicion followed by echocardiography evaluation is the key to diagnosing this condition. The traditional treatment modality is a surgical closure of a ruptured coronary sinus. There is less experience with transcatheter closure using Amplatz occluder [6]. Surgical procedure in this case is connected with a low risk of postoperative mortality [1,9-3,6\%] and with good long term results $[7,8]$.

\section{References}

1. Goldberg N, et al. Sinus of Valsalva Aneurysms Department of Medicine, State University of New York Health Science Center at Brooklyn, Brooklyn, New York, USA, 1990; 831-836

2. Lijoi A, Parodi E, et al. Un ruptured Aneurysm of the Left Sinus of Valsalva Causing Coronary Insufficiency Case Report and Review of the Literature. Tex Heart Inst J. 2002; 29(1): 40-44.

3. Peter JE, John SH, et al. Echocardiographic Diagnosis of Congenital Sinus of Valsalva Aneurysm with Dissection of the Inter ventricular Septum. Circulation. 1981; 63; 705-711. doi: 10.1161/01.CIR.63.3.705

4. Moustafa S, Mookadam F, et al. Sinus of Valsalva aneurysms-47 years of a single center experience and systematic overview of published reports. Am J Cardiol. 2007. 99: 1159-64. doi: 10.1016/j.amjcard.2006.11.047

5. Blackshear JL, Safford RE, et al. Unruptured noncoronary sinus of Valsalva aneurysm: preoperative characterization by transesophageal echocardiography. J Am Soc Echocardiogr. 1991; 4(5): 485-90. doi: 10.1016/S0894-7317(14)80382-9

6. Amplatzer Duct Occluder. Catheter Cardiovasc Interv. 2003; 58(3): 406-11

7. Kerem MV, Erol S, et al. Approach to sinus of Valsalva aneurysms: a review of 53 cases. Europan Journal Cardio-thoracic surgery. 2001; 20(1): 71-76. doi: 10.1016/S1010-7940(01)00758-8

8. Sarikaya $S$, Adademir $T$, et al. Surgery for ruptured sinus of Valsalva aneurysm: 25 years experience with 55 patients. Europan Journal Cardiothoracic surgery. 2013; 43(3): 591-96. doi: 10.1093/ejcts/ezs450

9. Doporučené postupy pro diagnostiku a léčbu chlopenních srdečních vad v dospělosti, J. Popelová et al. Cor et Vasa 2007 
10. Thomas JT, George JR. Sinus of valsalva aneurysm or fistula : management and outcome, Presented at the Thirty-fourth Annual Meeting of the Society of Thoracic Surgeons. New Orleans, LA. 1998; 26-28. doi: 10.1016/ S0003-4975(99)01045-0

11. Prafulla G, Kerkar, Charan P. Lanjewar Transcatheter closure of ruptured sinus of Valsalva aneurysm using the Amplatzer duct occluder: immediate results and mid-term follow-up. European Heart Journal. 2010; 31(23): 2881-87. doi: 10.1093/eurheartj/ehq323
12. Edwards JE, Burchell HB. The pathological anatomy of deficiencies between the aortic root and the heart, including aortic sinus aneurysms. Thorax. 1957; 12(2): 125-39.

13. Guo DW, Cheng TO, Lin ML, Gu ZQ. Aneurysm of the sinus of Valsalva: a roentgenologic study of 105 Chinese patients. Am Heart J. 1987; 114(5): 1169-77. doi: 10.1016/0002-8703(87)90193-1 